\title{
Sacredness to desecration: 'Languaging' and 'othering' of peoples and places through dumping of domestic waste in Urora, Benin City, Nigeria
}

\begin{abstract}
Hope Iyawe*
This paper examines the dynamics of environmental change of physical spaces and the behaviour of the residents of a formerly close-knit community whose belief systems are contrary to their lifeworld situation as observed in Urora settlement in Benin City, Nigeria. The findings revealed that the satellite images show that the study area was much greener 20 years ago and environmentally attractive compared to the current time. Lack of infrastructure such as waste bins has led to a shift in mindset among the residents to accommodate illegal dumping contrary to attitudes in the past. Population growth and refuse generation and disposal is also a significant challenge. Based on the findings, the paper posits for the realignment and reconsideration of the embodied sacredness of nature with the mode of expression of the past which was pro-environmentally inclined and focussed.
\end{abstract}

Keywords: sacredness, desecration, languaging, othering, domestic waste

\section{Introduction}

Urora's lifeworld has parallels with some settlements of sub-Saharan cities. Most residents in formerly close-knit communities in sub-Sahara African countries experience some degree of human-human-environment dislocations as their areas undergo population explosion especially due to rapid urbanisation (Ogu, 2000). One example of this dislocation arises from inadequate waste management services which force residents to live contrary to their belief systems regarding sanitation, thus contributing to cognitive dissonance. Evidence abounds that the majority of residents in sub-Saharan African cities subscribe to spiritual belief systems which 
are against indiscriminate waste disposal (Millar et al., 2005; Ajala, 2011; Ojedokun and Balogun, 2013; Iyawe, 2019). In some communities, certain spaces are designated as sacred in line with peoples' specific religious beliefs. However, increasing urban sprawl, population explosion and inadequate physical planning/infrastructural development have contributed to escalation in solid waste disposal challenges.

The scenario of waste disposal has, in turn, affected residents' language of interaction as they communicate with one another especially when trying to achieve the balance between normative goal of cleanliness and godliness on the one hand; and on the other hand, dispose refuse indiscriminately due to weak management services (Iyawe 2019). Researchers have agreed that the language of interaction defines implicitly or explicitly human beings in the world as the exercise is a product of engagement of the competing individual wants and desires (Becker, 1991). Consequently, in this lifeworld situation, sounds from the style of communication/expression have become contrary to the meanings they are supposed to convey in the ensuing exchange of living together in the community. In the sociological context, the process whereby a majority or a minority constructs a shared 'UsThem' representation of another group by using discourses of class, gender and social order is referred to as 'othering' (Palfreyman, 2005, Zabus, 1990). Adesanmi (2011) describes otherness as how people see themselves as the 'norm' while seeing others who do not 'look' like them as inferior, primitive and anomalous. The resultant social identities reflect how individuals and groups internalise stereotyped social categories within their social systems. The use of class, gender and social order distinctions appears to resonate among different communities globally where issues of cultural differences, language barriers and religious persuasions seem to have taken centre stage in the day to day lives of the people (Medina, 2000; Adesanmi, 2011).

Given these developments and from the perspectives of the everyday life, the study presents a picture of a transition from sacredness to the desecration to illustrate the dynamics of environmental change of the physical space and the resultant behaviour of residents. This change is analysed within the full cycle of waste from the source to waste to the dump as well as change in the languaging involved. Using ethnographic and phenomenological data, the study explains how once a rich natural environment with sacred grooves became degraded through ad-hoc developments and the resultant indiscriminate waste disposal. The relationship between sacred natural environment and desecration of the landscape has escalated primarily due to the intensification of activities of rural-urban migration and spatial expansion. Thus, for the peoples' well-being, the dynamics of environmental change and the behaviour of residents in response to waste management challenges through languaging and practices of waste disposal are not mutually isolated but can be assumed rhizomatically as reciprocally influential. The paper, therefore, contributes 
to an understanding of the environmental change of physical spaces and the environmental behaviour of low-income residents whose belief systems and cosmovision stands contrary to their daily live experiences (see Figure 1). The four key objectives of the reported study are;

- To illustrate that indiscriminate waste disposal strongly correlates with inadequate planning, population explosion due to rapid urbanisation and the erosion of cultural and religious values:

- To illustrate the extent to which the mother-tongue language of the community (as a means of communication/expression during waste generation and disposal) has changed over time in tandem with the changing landscape.

- To substantiate on why residents desecrate certain places while largely sparing religious and residential places.

- To demonstrate the significance of kinship, age and gender considerations ("in/out-group") in relation to assigning roles and responsibilities and how this is being challenged by itinerant push-cart and scavengers as an emergent component of the waste disposal cycle.

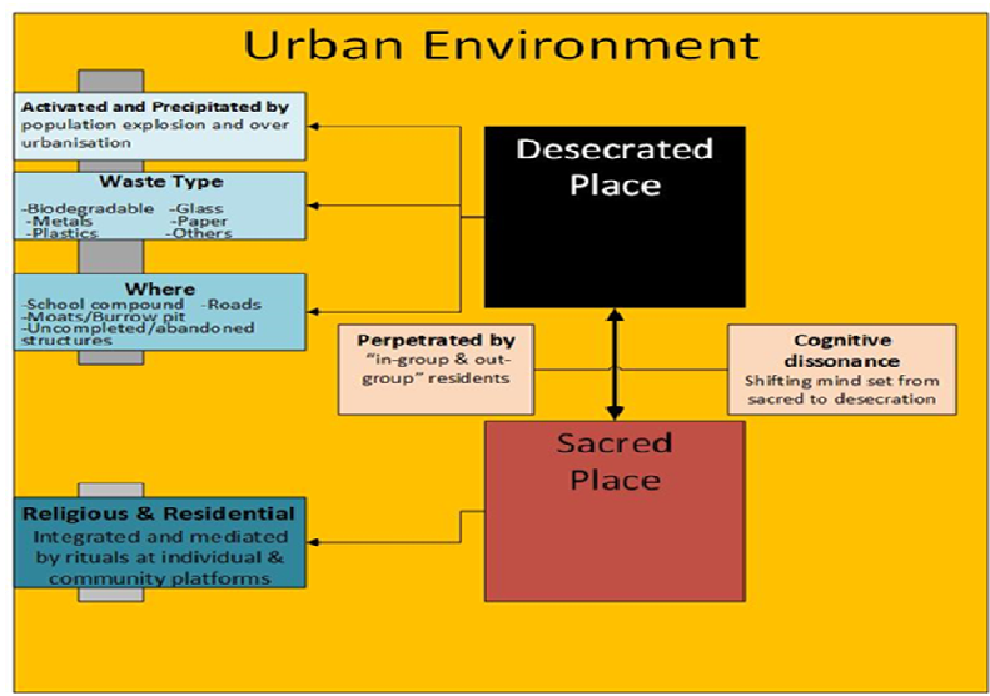

Figure 1. Conceptual mapping of environmental and behaviour change of Urora residents

\section{Research methodology}

\subsection{Study area: Urora}

Urora lies between latitudes $6^{0} 22^{\prime} 04^{\prime \prime}, 6^{0} 22^{\prime} 43^{\prime \prime} \mathrm{N}$ and longitudes $5^{0} 41^{\prime} 11^{\prime \prime}$, $5^{0} 42$ '23" E with a population of 48219 (2018 estimate projected from the 2006 
National Population Census). It is situated within Ikpoba-Okha Local Government Council which is one of the 18 local councils of Edo state. Idogbo, which serves as the administrative headquarters of the council is about 20 kilometres away from Urora. However, the study location has been engulfed by Benin City, the state capital, due to population explosion especially arising from rapid urbanisation (see Figure 2). Ikpoba-Okha has a projected population of 425860 on a land area of $862 \mathrm{~km}^{2}$ and a density of 494 inhabitants per $\mathrm{km}^{2}$ (2011 estimate of population from the 2006 National Population Census).

On traditional administrative setup, while the Oba holds sway in Benin City and beyond (as other traditional leaders are hierarchically subordinate to the Oba), the neighbouring communities have Enigies (plural for Enogie) as their traditional heads, Urora has a traditional priest (Ohen). This arrangement may explain the presence of the shrine close to the main entrance to the community and also the celebration of certain feasts and festivals (such as Igue and Ikpoleki) at certain times of the year. Traditionally, and also for contemporary administrative convenience, the settlement is sub-divided into three quarters, namely Urora I (Ohen quarters), Urora II (across the Benin-Okene-Abuja highway), and Urora III (Aideyanba Quarters). Each of these quarters has their local traditional head as chiefs or Ohen.

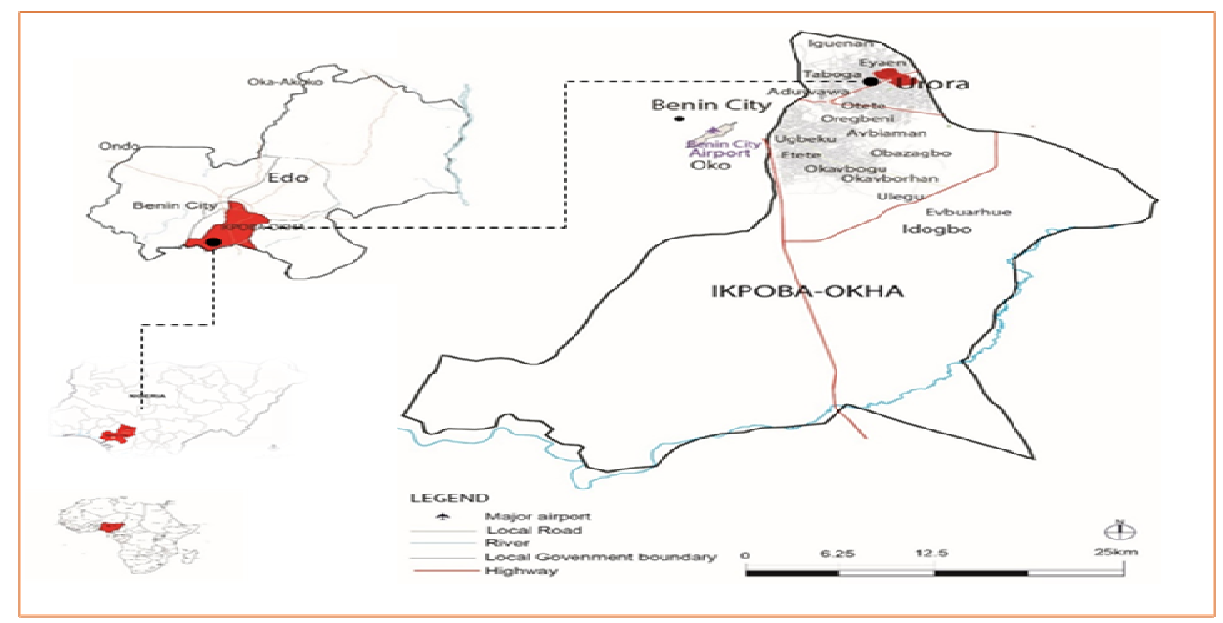

Figure 2. Map of Edo state showing Ikpoba-Okha and Urora

Source: ESMLH,1990

\subsection{The phenomenological and ethnographic study}

The study adopted a combination of phenomenological and ethnographic approaches which focussed on the essence and lived experiences of resident 
participants as the researcher used four and half months while assuming a participant-observation in the fieldwork. The phenomenological research aimed at suspending prior value judgements and focusing on pursuing the meaning of the phenomena from the perspective of the participants' experiences. This approach focused on participants' awareness, experiences and related responses to the solid waste. The interview questions sought to explore the lived experiences especially around the themes such as sacredness, desecration and language adaptations. Examples are:

- What is the local understanding of the concept of waste (mothertongue words and what they connote)?

- In your mother-tongue is there a word for the people who handle waste?

- Describe your experience/encounter with the solid waste disposal/management process from generation at home to disposal at the public open space, would you say there is a specific person assigned the role to sweep/pack/dispose solid waste on a regular basis?

- $\quad$ Any particular reason why it should be that person and not other members of the household?

- How regularly is the solid waste generated and disposed from the homestead?

- With what container(s) is the solid waste disposed from the homestead?

- What value do they place on waste?

- Would the head of households be involved in waste management/disposal?

\subsubsection{Data collection}

Data for the study were collected as part of more extensive research conducted throughout 4 and half months between November 2016 to March 2017 and July 2017. The study has four main stages: Stage 1 involved GPS in order to produce an updated base map with readings of meaning-making features of the settlement as none was readily available. The production of the map was complemented with the production of the 1997 and 2017 historical satellite imagery of the area to show at a glance the trend of physical developments in the area over the last 20 years (see Figure 3). The primary data collection stage of the study was facilitated by a resident gate-keeper/key informant who guided the researcher around to see the settlement.

\subsubsection{Data presentation of place, 'inner-to-outer' and 'othering}

Rural-urban migration, population explosion and the unbridled urbanisation of Benin City has had a spill-over effect on the settlement of Urora. In particular, the 
built area has increased by $58 \%$ while the vegetation has decreased by almost $100 \%$ over a twenty-year period (see Figure 3).

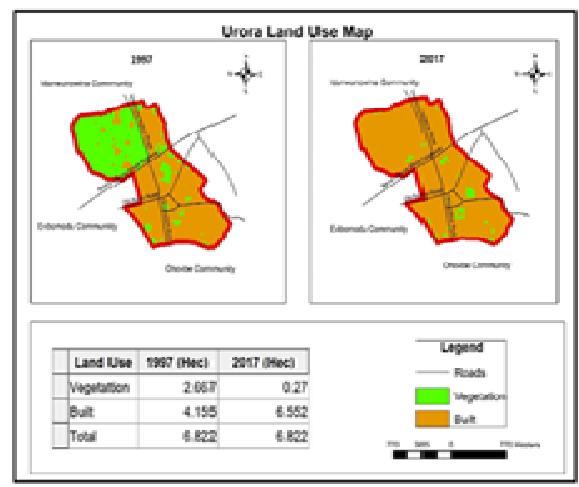

A

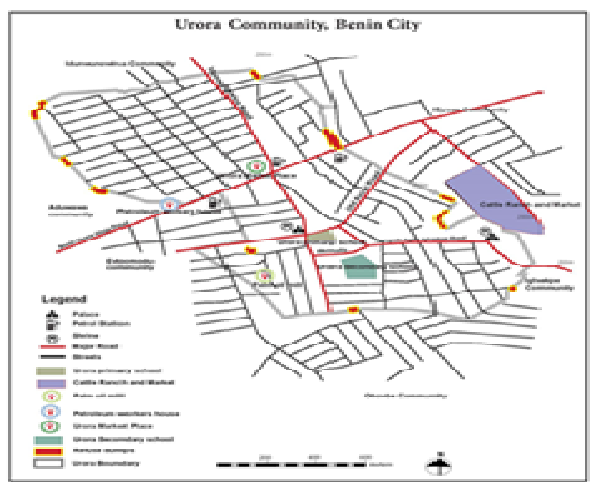

B

Figure 3a. Satellite Imagery of Urora community 1997 and 2017

Source: ESMLH, 1990

Figure 3b. Urora community showing the roads and PA features

Source: Field survey November 2016-March 2017

\subsubsection{The solid waste story of research participants}

After shadowing these households for five days, the researcher undertook an in-depth phenomenological interview in the homes of 3 heads of households selected according to the following criteria:

- Head of household, a population of seven, non-Urora indigene, a Christian.

- Head of household, population of seven persons, Urora indigene, a new convert from ATR to Christianity.

Another interesting aspect of the study is the inclusion of an indigene to shed some light on the use of the host community mother tongue in the solid waste story. The reason for this was purely pragmatic as I had access to the three heads of households. Therefore, part of the focus of this paper is to re-live the experience of waste generation and disposal activities that facilitated the physical conditions of the settlement from sacredness to desecration.

- Head of household, family population of eight persons, non-Urora indigene, a Muslim.

\subsubsection{A case study of the three families}

The household is a Christian family size of seven headed by a 50 -year-old businessman and lives at the boundary between Urora and Eyaen communities (approximate location marked " 3 " on Figure 4). Table 1 presents the solid waste gen- 
erated by this family for about five days in different categories from March 6-10, 2017.

Table 1. Waste composition per capita and in percentage, Christian family, a population of 7, off Idunmwunowina

\begin{tabular}{|l|l|}
\hline Waste type & Kg \\
\hline Biodegradable & 0.9 \\
\hline Plastics & 0.71 \\
\hline Putrescible & 1.2 \\
\hline Paper & 0.4 \\
\hline Glass & - \\
\hline Metals & 0.01 \\
\hline Textiles & 0.3 \\
\hline Others & - \\
\hline Total & $\mathbf{3 . 5 2}$ \\
\hline
\end{tabular}

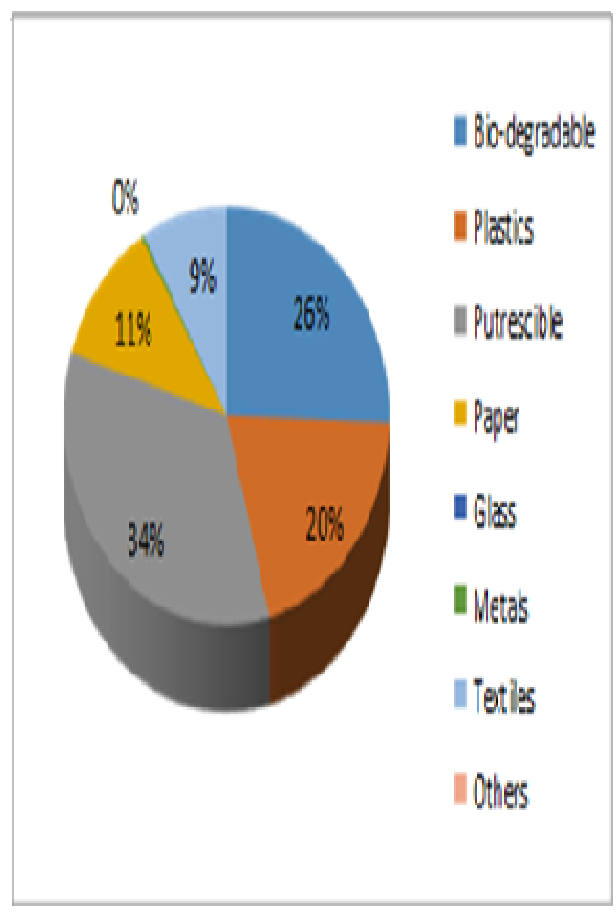

Figure 4. Solid waste generation

\subsubsection{Case study 2: The two households close to the formal cattle market}

From Fig.5a-b below shows the waste generated portrays the difference in living standards of the households. The itinerant cart-pushers gather waste (which could include solid wastes of more than one household) in Jute bags from clients as the vendor moves from house to house soliciting for more waste (Plate 1). 


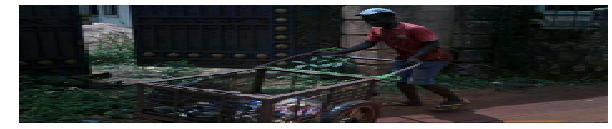

Plate 1

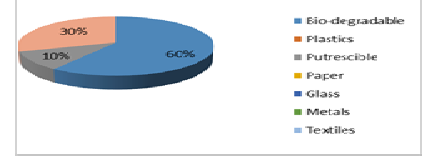

B

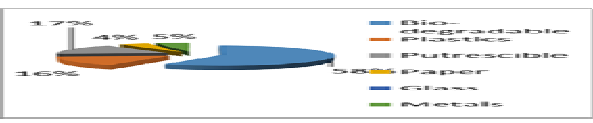

A
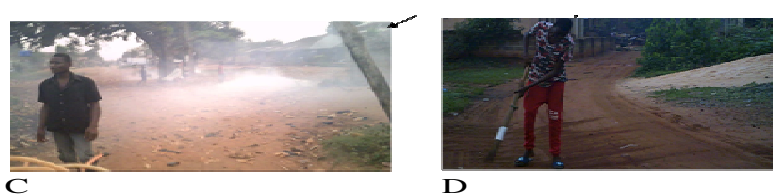

Plate 1. Push-cart vendor during operation, solid waste generation at Aideyamba (a), solid waste generation at cattle market (b), open-air burning of solid waste (c ), and compound sweeping $(\mathrm{d})$.

\section{Results and discussion}

The satellite images in Figure 3 shows that the total built area increased $58 \%$ from 4155 to 6552 hectares over a 20 -year period and a corresponding decrease in vegetation cover of almost $100 \%$. The expansion of housing units reflects increased urbanisation and population migration from the hinterland to Benin City, the state capital. As expected, the demand for available spaces for other activities apart from housing has increased astronomically with the almost non-availability of vacant land for future expansion. As a result, street corners, public open spaces, trench/ burrow pits/ dug-out moats have become alternative spaces for waste disposal by residents (Figure 4 and 5a). Given this scenario, and coupled with the inability of the municipality to cope with waste management provision, previously protected areas have been exposed to indiscriminate waste disposal. This arrangement suggests that residents are no longer restrained from generating and disposing waste indiscriminately to the detriment of the environment. Thus, the results corroborate Tedeschi et al. (1971) study that if there exist such constraints people are likely to pollute their environment even when their belief systems tell them otherwise, thus manifesting a clear example of cognitive dissonance. Given this lack of restraint, disorder is bound to spread.

While waste is dumped indiscriminately in public open spaces, the current study found that there are exceptions in individual homes and places of worship. From the action focus (orthopraxy) perspective, we can argue that since most of the residents are somewhat religious, they tend to obey personalities, authorities and comply with laid down rules and regulations which is why they do not desecrate certain places. This position supports Alcorta and Sosis (2005) observations that ritual, emotion and holy symbols find spatial, emotional and behavioural dimensions and adaptations- that residents adapt to what they see as long as body, brain and environment are in agreement-embodiment. 
Age, gender and kinship expectations, which form the basis for assigning roles and responsibilities within the family and community, are at present complimented by push-cart operators and itinerant scavengers. Informal waste-pickers have emerged from the over urbanisation of and population explosion in Benin City. This fact correlates with studies by Wilson et al. (2009) who argue that as the population escalates a fraction of the people will engage in some of the informality to make a living. The definition of age, gender and kinship nexus comprise part of the "in-group", and at the same time, "out-group" categories, as it possesses a more encompassing definition than otherwise known. Therefore, since there exists roles and responsibilities predicated on gender, age and kinship considerations the issue of "us" and "them" will continue even within the nuclear family.

\section{Conclusion}

The study focused on the interrelationships between changes in the environment of physical spaces and residents' attitudes through the lens of religion, psychology and phenomenology/neurophenomenology in Urora. Urbanisation, population explosion and erosion of community values were revealed to be responsible for the desecration of spaces that were once held as sacred. Given the existentialphenomenological view that humans do not stay in their actualities but in their possibilities, the language of communication and expression have been modified to adjust to the general situation-as language is far removed from its meanings. Given the advantages and potentials presented by the research community, there is every possibility that a realignment and reconsideration of their embodied sacred nature with the mode of expression of the past be advocated for human-humanenvironment sustainability. The language was seen as purposely led, ordered and conditioned. Rather than being repulsed by the activities of polluters, it appears community leaders are sympathetic to people with filthy tendencies and overwhelmed by these happenings as other residents pretend as if nothing has happened. In post-colonial African urban centres, the phenomena explored in this study appear to find spatial expression as the indigenous community which play host to other residents tend to be heterogeneous in outlook.

Acknowledgment. I greatly thank my lovely wife for her show of understanding. In addition, I appreciate the contributions carried out by Engr. Olotu Yahaya.

\section{References}

[1] Adesanmi P., You're not a country, Africa. A personal history of Africa present, Penguin Books, Random House South Africa, 15(3), 2011, pp. 322358. 
[2] Ajala A.S., Space, identity and health risks. University of Pittsburgh, USA 2017. http://hcs.pitt.edu, Accessed 12 July 2017.

[3[ Alcorta C.S., Sosis R., Ritual, Emotion, and Sacred symbols, Human Nature, 16(4), 2005, pp. 323-359.

[4] Becker A.L., Language and Languaging, Language and Communication, 11(2), 1991, pp.33-35.

[5] ESMLH., Bulletin of Edo State geographical location, DIVA-GIS and Edo State Ministry of Lands Surveys, 20(2), 1990, pp.400-415.

[6] Iyawe H., Place attachment and pro-environmental behaviour paralysis: A study of household solid waste management, Journal of Construction Project Management and Innovation, 9(1), 2019, pp. 72-84.

[7] Medina M., Scavenging cooperatives in Asia and Latin America. Resource conservation recycling, 31(2), 2000, pp 51-69.

[8] Millar D., Kendie S.B, Apusigah A.A, Haverkort B., African knowledge and Sciences: Understanding and supporting the ways of knowing in Sub-Saharan Africa, Compass series on Worldviews and Sciences 3 Papers and Proceedings of an International Conference of African Knowledges and Sciences. Oct. 23-29, 2005, Bolgatanga U/R Region Ghana, pp. 40-50.

[9] Ogu V.I., Waste management in Benin City: Private sector and municipal waste management in Benin City Nigeria, Environment \& Urbanization, 12(2), 2000, pp. 103-117.

[10] Ojedokun O., Balogun S.K., Self-monitoring and responsible environmental behaviour: The mediating role of attitudes towards littering, Frontiers in Psychological and Behavioural Science, 2(1), 2013, pp.31-38.

[11] Palfreyman D., Othering in an English language program, TESOL Quartely, 39(2), 2005, pp.211-233.

[12] Tedeschi J.T., Schlenker B.R., Bonoma T.V., Cognitive Dissonance: Private ratiocination or public spectacle? American Psychologist, 26(3), 1971, pp. 685-695.

[13] Wilson D.C., Araba A.O., Chinwah K., Cheeseman C.R., Building recycling rates through the informal sector, Waste Management, 29(2), 2009, pp.629635.

[14] Zabus C., Othering the foreign language in the West African Europhone Novel, Canadian Review of Comparative Literature, 21(3), 1990, pp.450-455.

Address:

- Dr. Hope Iyawe, Department of Urban \& Regional Planning, Auchi Polytechnic, Auchi, Edo State, Nigeria: hopeiyawe2@gmail.com ("corresponding author) 